\title{
Análise das Características do Discurso Populista de Jair Bolsonaro nas Eleições Brasileiras de 2018
}

\author{
Vinicius Albernaz ${ }^{\star}$ \\ * Universidade da Beira Interior, Portugal
}

\begin{abstract}
Resumo
Este trabalho busca analisar as principais características da ascensão do populismo no Brasil, através do discurso político, nas eleições de 2018, do presidente Jair Bolsonaro e o seu impacto na sociedade brasileira. A metodologia utilizada na presente investigação se dá através da pesquisa teórica, exploratória com revisão bibliográfica e utilização do método de análise do discurso de Vargas et al. (2018). Este trabalho divide-se em três grandes eixos, sendo apresentado: (1) o percurso crítico do populismo, (2) populismo e neopopulismo na América Latina e (3) as caraterísticas do populismo de Jair Bolsonaro no Brasil. O estudo leva-nos a concluir que o seu discurso se caracteriza fundamentalmente por um discurso político populista contemporâneo na América Latina.
\end{abstract}

Palavras-chave: populismo; discurso; Jair Bolsonaro; eleições; Brasil

\begin{abstract}
This paper seeks to analyze the main characteristics of the rise of populism in Brazil through the political discourse in the 2018 elections of President Jair Bolsonaro and its impact on Brazilian society. The methodology used in the present investigation is a theoretical, exploratory research with literature review and the use of the discourse analysis method of Vargas et al. (2018). This work is divided into three main axes: (1) the critical path of populism, (2) populism and neopopulism in Latin America and (3) the characteristics of populism of Jair Bolsonaro do Brazil. The study leads us to conclude that his speech is fundamentally characterized by a contemporary populist political discourse in Latin America.
\end{abstract}

Keywords: populism; speech; Jair Bolsonaro; elections; Brazil 


\section{Introdução}

A ascensão de Jair Bolsonaro ao poder máximo no Brasil, recém-eleito presidente, se parece com a ascensão de outros políticos no mundo que utilizam-se de uma retórica parecida, como Donald Trump, presidente dos Estados Unidos da América (EUA), Rodrigo Duterte, presidente das Filipinas, Viktor Orbán, primeiro-ministro da Hungria, entre outros líderes na Europa. Com este pano de fundo, o objetivo central deste estudo desvela-se na tentativa de colaborar no entendimento destes acontecimentos, onde se emerge o olhar de diversos analistas políticos sobre a trajetória e retórica de Jair Bolsonaro, na qual o mundo debate como lhe chamar: populista? fascista? extremista de direita? risco a democracia?

As perspectivas no sentido de entender a forma populista do discurso de Jair Bolsonaro constituem o átrio da análise presente. Num conturbado contexto sociopolítico de eleições no Brasil no ano de 2018, o problema desta pesquisa visa responder a seguinte indagação: Quais são as principais características do discurso político de Jair Bolsonaro que o distingue como populista?

No que se refere aos termos metodológicos, na presente investigação optámos pela utilização de uma pesquisa teórica, exploratória, com revisão bibliográfica, técnica que nos propusemos aplicar tendo em vista a sua adequação e tradição para explicação do fenômeno abordado em questão. De modo específico, este estudo tem como objetivo sistematizar parte dos conhecimentos produzidos e refletir teoricamente sobre o discurso populista de Jair Bolsonaro utilizando o método de Vargas et al. (2018) para análise do discurso.

Este trabalho inicia-se com elementos introdutórios sobre o populismo no âmbito da democracia representativa. Aborda-se teoricamente sobre o populismo na conjuntura do modelo das democracias liberais contemporâneas. Para caracterizar o discurso da candidatura, Vargas et al. (2018) identificaram, selecionaram e analisaram um conjunto significativo de falas, textos e/ou performances expressas em eventos públicos (comícios, entrevistas, anúncios televisivos), declarações à imprensa, mensagens e postagens nas mídias sociais, que foram feitas ou expressas desde o segundo semestre de 2017 até agosto de 2018. Por um lado, o "Nós", Cidadãos de bem e o "Eles", Esquerdistas,

Portanto, como forma de abordar objetivamente, este trabalho divide-se em três grandes eixos sendo apresentados: (1) Populismo: percurso crítico, (2) Populismo e neopopulismo na América Latina e (3) As caraterísticas do discurso populista do candidato Jair Bolsonaro. Ao final do artigo, apresenta-se a ideia central acerca dos principais pontos do discurso político de Jair Bolsonaro que nos leva a concluir que o seu discurso se caracteriza fundamentalmente por um típico discurso político populista.

\section{Populismo: Enquadramento Teórico}

O populismo é um fenômeno político de difícil definição, não é consensual, é bastante contestado por parte da academia científica, pois se utilizado de maneira ten- 
denciosa ou pormenorizada, quase sempre é uma afirmação política (Galito, 2017). Segundo Carneiro (2009, p. 8) “o populismo é uma forma de fazer política associada ao emprego de um discurso característico, que recorre à determinadas estratégias de mobilização e organização com vistas a atingir clientelas e eleitores".

Lincolins, Yazbek e Vasconcellos (2018) afirmam que o berço do populismo surgiu na democracia ateniense, com Cléon de Atenas (?-422), político altamente carismático com novo estilo de discurso, que concedeu vários benefícios populares e iniciou uma ampla perseguição aos adversários. O termo "populismo" é uma das principais palavras em voga na atualidade, bastante utilizada no século xx. Divisões ideológicas, históricas e geográficas intervém na tentativa de conceitualizá-lo. Possui uma natureza camaleônica, pois renasce em diferentes contextos possuindo uma capacidade de sobrevivência e resistência a adversidade (Galito, 2017).

Para Mouffe (2016) o populismo não é um regime político ou uma ideologia, e não pode ser atribuído a um conteúdo programático específico. É totalmente compatível com diferentes formas de governo. É uma maneira de fazer política que pode assumir várias formas, dependendo dos períodos e dos lugares. Esta maneira segundo a autora, surge quando se pretende construir um novo sujeito de ação coletiva - o povo - capaz de reconfigurar uma ordem social vivida como injusta.

O vocábulo populismo é comumente utilizado para falar de presidentes de esquerda da América Latina ou presidentes de direita dos Estados Unidos e/ou da Europa. De acordo com Mudde \& Kaltwasser (2017), no contexto da América Latina, o populismo trata-se muitas vezes de uma má gestão econômica e clientelismo, porém na Europa diz respeito frequentemente a anti-imigração e xenofobia.

Mouffe (2016) reforça esse pensamento ao destacar que em diversos países europeus, esse desejo de recuperar a soberania foi conquistado por partidos populistas de direita que conseguiram construir o povo através de um discurso xenófobo que exclui os imigrantes, considerados uma ameaça à prosperidade nacional. Esses partidos estão construindo um povo cuja voz exige uma democracia destinada a defender exclusivamente os interesses daqueles considerados "verdadeiros cidadãos".

De acordo com Gidron e Bonikowski (2013) as três principais linhas de investigação na atualidade sobre populismo, são ideologia política, um estilo político ou uma estratégia política, conforme apresentado na Tabela 1 .

O populismo, na qualidade de ideologia, divide dois grupos políticos homogêneos. Nesse sentido, a definição de populismo de acordo com Mudde \& Kaltwasser (2017) é:

uma ideologia de baixa densidade que considera que a sociedade está, em última instância, dividia em dois campos homogêneos e antagônicos - o povo puro versus a elite corrupta - e que defende que a política deveria ser uma expressão da volonté générale (vontade geral) do povo (Mudde \& Kaltwasser, 2017, p. 18). 
Tabela 1. Características das três abordagens à pesquisa do populismo

\begin{tabular}{|c|c|c|c|c|}
\hline & $\begin{array}{l}\text { Definição de } \\
\text { Populismo }\end{array}$ & Unidade de Análise & Métodos relevantes & Referências \\
\hline $\begin{array}{l}\text { Ideologia } \\
\text { Política }\end{array}$ & $\begin{array}{l}\text { Conjunto de ideias } \\
\text { interelacionadas } \\
\text { sobre a natureza } \\
\text { sociopolítica }\end{array}$ & $\begin{array}{c}\text { Partidos e líderes } \\
\text { partidários }\end{array}$ & $\begin{array}{l}\text { Literatura partidária. } \\
\text { Análise qualitativa } \\
\text { dos textos }\end{array}$ & $\begin{array}{l}\text { Mudde }(2004,2007) \\
\text { Mudde e Kaltwasser } \\
\text { (2012) }\end{array}$ \\
\hline $\begin{array}{l}\text { Estilo } \\
\text { Político }\end{array}$ & $\begin{array}{l}\text { Discurso com } \\
\text { características } \\
\text { específicas para } \\
\text { reinvindicação } \\
\text { política }\end{array}$ & $\begin{array}{c}\text { Textos } \\
\text { Discursos }\end{array}$ & $\begin{array}{c}\text { Análise } \\
\text { interpretativa dos } \\
\text { textos }\end{array}$ & $\begin{array}{l}\text { Kazzin (1995) } \\
\text { Laclau (2005) } \\
\text { Panizza (2005) }\end{array}$ \\
\hline $\begin{array}{l}\text { Estratégia } \\
\text { Política }\end{array}$ & $\begin{array}{l}\text { Uma forma de } \\
\text { organização e de } \\
\text { mobilização }\end{array}$ & $\begin{array}{c}\text { Partidos (com } \\
\text { enfoque nas } \\
\text { estruturas), líderes e } \\
\text { movimentos sociais }\end{array}$ & $\begin{array}{l}\text { Análise histórica } \\
\text { comparativa e } \\
\text { estudos de caso } \\
\text { (case studies) }\end{array}$ & $\begin{array}{l}\text { Roberts (2006) } \\
\text { Weyland (2001) } \\
\text { Jansen (2011) }\end{array}$ \\
\hline
\end{tabular}

Fonte: Baseado em Gidron e Bonikowski, 2013:17.

Para Mouffe (2000), em sua obra The democratic paradox, discorda que a relação política, obrigatoriamente, tenha que ser uma relação amigos e inimigos, ela acredita que a tarefa da política democrática é exatamente esta, proporcionar as condições para que o antagonismo (relação com um inimigo) seja transformado em agonismo (relação com um adversário). É por este motivo que seu modelo radical de democracia também é chamado de agonístico:

Envisaged from the point of view of 'agonistic pluralism, the aim of democratic politics is to construct the 'them' in such a way that is no longer perceived as an enemy to be destroyed, but as an 'adversary', that is, somebody whose ideas we combat but whose right to defend those ideas we do not put into question (Mouffe, 2000, p. 101).

O populista, enquanto estilo político, possui as seguintes características peculiares: atributos carismáticos, oradores amáveis, culto à personalidade, simpáticos, muito-falantes. Entretanto, podem caracterizar-se também como: discurso agressivo, teimoso, arrogante. Depende da postura no melhor contexto em análise (Galito, 2017).

Mudde \& Kaltwasser (2017, p. 82) ressaltam ainda que, “os líderes populistas têm em comum: apresentam-se como a voz do povo, o que quer dizer ao mesmo tempo como outsiders políticos e como genuínos representantes do povo comum”.

O populismo, enquanto estratégia política, visa lutar contra a exclusão, por uma maior redistribuição dos recursos, enfraquecer as instituições democráticas, pois acredita-se que estão contaminadas pela ideologia adversária. Pode ser guiada por um líder que deseja governar, ou que espera continuar a fazer o uso do poder, apelando ao voto de um grande número de apoiadores que confiam nele de forma direta, não organizada e não institucionalizado (Galito, 2017). 
Deste modo, apesar de algumas divergências entre os principais estudiosos sobre o populismo, todos estão de acordo que as formas existentes de populismo são de alguma maneira um apelo ao povo e uma contundente denúncia as elites (Laclau, 2005). Neste contexto, vale ressaltar que o populismo não é de forma específica um regime político ou governo, e sim um sentido político que tem uma característica: designar o povo na sua relação antagônica contra os poderosos.

O entendimento de Mudde \& Kaltwasser (2017) respondem as principais críticas ao termo que é essencialmente um termo de luta utilizado para denunciar um adversário político aplicando-se a todos os personagens políticos. Portanto, o populismo é utilizado generalizadamente com uma grande carga negativa para atacar os opositores dos diversos segmentos políticos divergentes.

De acordo com Galito (2017) ser popular e ser populista são amplamente divergentes. O líder é populista se o seu programa caracterizar por ser anti-sistêmico; é popular se buscar satisfazer as demandas do povo com soluções que não destruam o Estado de direito democrático. A estratégia popular é segura, protetora, moderada e construtiva. A populista é perigosa, paternalista, extremista e destrutiva. Conclui-se a partir da Tabela 2 que a principal diferença está nos excessos.

Tabela 2. Diferenças entre Popular e Populista

\begin{tabular}{cc}
\hline Popular & Populista \\
\hline Sistémico & Anti-sistémico \\
Ordem democrática & Desordem democrática \\
Moderado & Extremista \\
Medidas concretas & Plano difuso \\
Promessas que cumpre & Promessas que não cumpre \\
Protetor & Paternalista \\
Previsível & Imprevisível \\
Realista & Idealista \\
Crítica construtiva & Crítica destrutiva \\
Seguro & Perigoso \\
\hline
\end{tabular}

Fonte: Recuperado de "Populismo - conceptualização do fenômeno" de Galito, M.S, 2017, p. 22.

Este trabalho corrobora nos estudos sobre o populismo no âmbito da democracia representativa, além de se posicionar teoricamente sobre o populismo na conjuntura do modelo das democracias liberais contemporâneas. De acordo com Pasquino (2010) as democracias liberais caracterizam-se por: 
a) os direitos civis e políticos são reconhecidos e tutelados; b) afirma-se e respeita-se o Estado de direito, c) a magistratura é independente; d) existe uma sociedade pluralista com meios de comunicação independentes do poder político; e) os civis controlam os militares (Pasquino, 2010, p. 355).

Mudde \& Kaltwasser (2017) entendem empiricamente que os agentes políticos populistas mais importantes surgem num contexto democrático liberal, ou que tem o desejo de serem democráticos liberais. Mouffe (1996, p. 184) afirma que o liberalismo político proclama a necessidade de um tipo de consenso moral e que os valores e os ideais desempenham um papel autoritativo.

Nesse sentido, Carneiro (2009) afirma que os líderes populistas recorrem ao socialismo, nacionalismo, ou até mesmo o liberalismo, pois ligam-se a diferentes ideologias e grupos para sua sobrevivência. Numa democracia liberal, o Estado tem uma clara delimitação do seu poder e a preservação da esfera dos direitos individuais, ou seja, o Estado é definidamente um Estado fraco (Fukuyama, 1999).

O populismo de direita surge em contextos de países ricos, com obsessão em reafirmar ou recuperar os valores sociais, culturais e sociais, relacionados com a identidade, da pátria e/ou nação. O populismo de esquerda surge no contexto de países com a maioria da população pobre, em desenvolvimento. Deste modo é possível observar esta dicotomia a partir da Tabela 3 , diferenciando o populismo de esquerda e de direita (Galito, 2017).

Tabela 3. Características do Populismo

\begin{tabular}{|c|c|c|}
\hline EM COMUM & ESQUERDA & DIREITA \\
\hline Ideologia política & Progressista & Conservadora \\
\hline Antissistema & Criar novo modelo & Regressar a modelo do passado \\
\hline Programa político generalista & Mais Estado & Menos Estado \\
\hline Anticorrupção & Contra monopólios privados. & Contra monopólios públicos. \\
\hline $\begin{array}{l}\text { Manipulação das massas } \\
\text { (quantitativo) e das suas } \\
\text { expetativas (qualitativo). }\end{array}$ & Mais liberdade. & Mais segurança. \\
\hline $\begin{array}{l}\text { A favor do 'povo'. } \\
\text { (em nome do todo ou da maioria } \\
\text { marginalizada). }\end{array}$ & Modelo social público & $\begin{array}{l}\text { Mais responsabilidade social } \\
\text { privada. }\end{array}$ \\
\hline Discurso pela justiça social & Acabar com os ricos. & Acabar com os pobres. \\
\hline Antagonismo (bons e maus) & Luta de classes & Luta de poderes \\
\hline Tónica & Reivindicações socioeconómicas. & $\begin{array}{l}\text { Patriotismo/Nacionalismo. } \\
\text { Identidade cultural e/ou } \\
\text { religiosa. }\end{array}$ \\
\hline Radicalismo & Grupos dissidentes & Líder carismático \\
\hline Riscos & Ditadura do proletariado & $\begin{array}{l}\text { Tirania (um só líder todo } \\
\text { poderoso) }\end{array}$ \\
\hline
\end{tabular}

Fonte: Recuperado de "Populismo - conceptualização do fenômeno" de Galito, M.S, 2017, p. 12. 
Laclau (2005) afirma que a flexibilidade com que o conceito é aplicado a situações as mais contraditórias (tanto à direita como à esquerda) revela a dificuldade de entender o populismo. De acordo com Galito (2017) a diferença entre populismo de direita e populismo de esquerda estão nos seguintes pontos:

Se o populismo for uma força de esquerda a favor do povo pobre, o grupo rival é a elite rica de direita que governa de forma corrupta e que supostamente deve ser combatida pelo sofrimento que impinge à maioria. Se for um fenómeno de direita, almeja defender a "maioria silenciada" que não consegue a afirmar a sua cultura ou que precisa ser protegida de uma ameaça exterior (Galito, 2017, p. 10).

Entretanto, Mendonça (2014, p. 67) defende que "o populismo é vontade de democracia, vontade pura e simplificadora da realidade social [...] no exato momento da sublevação popular, o avesso da ordem institucional estabelecida”. Portanto, após entender o percurso crítico do populismo para alguns dos principais autores, entender o surgimento do populismo no Brasil e na América Latina serão exploradas logo a seguir.

\section{Populismo e Neopopulismo na América}

O termo "populismo", como conceito teórico é um dos temas mais controversos da ciência política latino-americana. Discorrer sobre o início do populismo no Brasil é um grande desafio, pois há falta de precisão no conceito, mesmo que haja consenso em torno de populismos clássicos como os de Vargas no Brasil, Cárdenas no México, Perón na Argentina nas décadas de 1930 a 1940, entre outros, que muitos analistas dizem tratar-se de casos próximos ao fascismo.

O populismo no Brasil é definido por Ianni (1968) da seguinte maneira:

O populismo brasileiro surge sob o comando de Getúlio Vargas e os políticos a ele associados. Desde 1930, pouco a pouco, vai se estruturando esse novo movimento político. Ao lado das medidas concretas, desenvolveu-se a ideologia e a linguagem do populismo. Ao mesmo tempo que os governantes atendem a uma parte das reivindicações do proletariado urbano, vão se elaborando as instituições e os símbolos populistas. [...] a entrada das massas no quadro das estruturas de poder é legitimada por intermédio dos movimentos populistas. Inicialmente, esse populismo é exclusivamente getulista. Depois, adquire outras conotações e, também denominações. Borghismo, queremismo, juscelinismo, janguismo e trabalhismo são algumas das modulações do populismo brasileiro (Ianni, 1968, p. 218).

De acordo com Laclau (2005) o potencial redistributivo dos Estados liberais e oligárquicos foi drasticamente reduzido pela crise e os sistemas políticos tornaram-se cada vez menos capazes de absorver as demandas democráticas. Isso levou a um abismo entre o liberalismo e a democracia, que dominaria a política latino-americana pelos próximos vinte e cinco anos. Vargas e o Estado Novo no Brasil, o peronismo na 
Argentina, os governos do Movimento Nacional Revolucionário na Bolívia, implementariam programas redistributivos e reformas democráticas sob regimes políticos claramente anti-liberais e, em alguns casos, excessivamente ditatoriais. Foi após a quebra da Bolsa de Nova York do início dos anos 1930, no entanto, que o Populismo latino-americano se tornou mais radical.

Vale ressaltar ainda que, Getúlio Vargas do Brasil era conhecido como o "pai dos pobres" devido a criação do Departamento de Imprensa e Propaganda (DIP) que construiu um culto a sua personalidade. Em seguida na década de 60, outro populista ocupou o seu lugar, foi o outsider Jânio Quadros que tinha como símbolo uma vassoura, devido ao seu jingle: "varre, varre vassourinha, varre a bandalheira". Após um governo com decisões contraditórias e controversas, Jânio Quadros renunciou, alegando perseguição de forças

O importante a salientar é que, em todos os casos, as "pessoas" constituídas através das mobilizações associadas a esses regimes tinham um forte componente estatista. A construção de um Estado nacional forte em oposição ao poder oligárquico local foi a marca registrada desse populismo (Laclau, 2005, p. 193).

Nos anos 1990, a América Latina viu emergir uma segunda onda de políticos populistas, os populismos "neoliberais" ou neopopulistas, como Fernando Collor no Brasil, Alberto Fujimori no Peru e Carlos Menem na Argentina. Baquero (2010) afirma que o termo "neopopulismo" tem sido utilizado para caracterizar movimentos ou partidos políticos que atuam dentro dos preceitos de uma poliarquia e economia de mercado, gerando um novo paradoxo, seja no aparecimento de líderes personalistas que seguem políticas neoliberais e, surpreendentemente, recebem um amplo apoio da população.

Carneiro (2009, p. 19) apresenta os principais critérios de classificação dos líderes neopopulistas que são: "1 - buscavam um forte apelo carismático na sua comunicação; 2 - sustentavam um discurso antipolítico; e 3 - polarizador; 4 - buscavam o apoio de clientelas específicas e 5 - recorreriam a uma estrutura de mobilização vertical para chegar ao poder".

A terceira onda do populismo caracterizou-se por um "populismo de esquerda" no início dos anos 2000, com os seus expoentes bolivarianos como Evo Morales na Bolívia, Rafael Correa no Equador, Hugo Chávez na Venezuela e seu pupilo sucessor Nicolas Maduro, com destaque também ao neoperonismo de Cristina Kirchner na Argentina. Cabe ressaltar ainda que, para alguns analistas o ex-presidente do Brasil, Lula da Silva, é considerado como neopopulista ou populista de baixa intensidade, pela forma característica de seus discursos em polarizar a sociedade em dois grupos antagônicos.

Para Baquero (2010, p. 184) “a prática política do neopopulismo - da mesma maneira que o velho populismo - se orienta na essência pelas regras tradicionais de dominação político-econômica”. As características em comum dos populismos latinos americanos se dão através de suas formas tradicionais de fazerem política com discursos críticos aos partidos e uma retórica de serem "antissistemas". 
Segundo Carneiro (2009) o líder populista faz do Estado seu patrimônio pessoal e, através da manipulação paternalista, recorre a estratégia de utilização dos recursos públicos de forma redistributiva para reparação da pobreza como forma de garantir a lealdade da população. O neopopulismo funciona com um clientelismo de massas através de políticas públicas de cunho assistencialista, nas classes menos favorecidas ou nos setores subalternos de modo a se constituir uma massa de manobra de líderes neopopulistas (Baquero, 2010).

Todavia, soma-se a isso os fatores de utilizarem comumente o discurso antagônico dos "nós" (cidadãos honestos, cidadãos de bem) contra o "eles" (elite política corrupta), equivalendo-se tanto para a esquerda, também ao centro e a direita, além de se auto intitularem os salvadores da pátria contra a elite corrupta, contra a paralisação econômica e o discurso divisor da sociedade nos dois grupos antagônicos (Mudde \& Kaltwasser, 2017).

No ano de 2018, durante a campanha eleitoral as presidenciais no Brasil, o adversário de Bolsonaro, Fernando Haddad do Partido dos Trabalhadores (PT), chegou a acusá-lo de ser um "extremista" e que representava um grande "risco" a democracia brasileira. O PT foi tão enfático em sua campanha que chegou a veicular uma campanha nas midea comparando Jair Bolsonaro a Adolf Hitler da Alemanha e ao partido nazista.

Recentemente o renomado cientista político, Francis Fukuyama, da Universidade de Stanford, nos Estados Unidos, afirmou que vê o risco da ascensão de um representante do que chama de "Internacional Populista" reiterando que os políticos de extrema direita com pouco ou nenhum apreço pela democracia e que seduzem os eleitores com promessas fáceis para problemas complicados. Fukuyama foi enfático sobre Bolsonaro dizendo: "Seria um grande desastre se ele fosse eleito. Ele parece ser um populista genuinamente perigoso, seu histórico demostra que ele não defende a democracia e que está usando está oportunidade para tomar o poder" (Amado, 2017).

Portanto, é possível concluir "que o populismo no Brasil é conhecido também como formação, apogeu e colapso da política de massas” Ianni (1968, p. 218). A seguir será demonstrada a singularidade do populismo de Jair Bolsonaro através da análise de suas principais características, posteriormente as nossas próprias considerações acerca do fenômeno.

\section{Análise Crítica das Caraterísticas do Discurso Populista de Jair Bolsonaro}

Jair Messias Bolsonaro nasceu em Campinas/SP, no dia 21 de março de 1955. Ingressou na reserva do Exército como Capitão em 1988 (por questões disciplinares, segundo depoimentos), e, desde então está no seu sétimo mandato parlamentar através de nove partidos, portanto, 27 anos de mandato como Deputado Federal.

No ano de 2014, Jair Bolsonaro foi o deputado federal mais votado no Rio de Janeiro com 464.572 votos, naquele momento suas bandeiras políticas já captavam fortemente o sentimento de bipolarização política que se avizinhava nos eleitores 
do Brasil, cansados da polarização Partido dos Trabalhadores (PT) versus Partido da Social Democracia Brasileira (PSDB). Na campanha de 2014, em busca de ser reconhecido, afirmava que as "suas bandeiras políticas são fortemente combatidas pelos partidos de ideologia esquerdista" (grifo nosso).

Almeida (2019) destaca que o discurso de setores à esquerda sobre ética na política no Brasil entrou em declínio, devido aos diversos escândalos de corrupção durante o governo do Partido dos Trabalhadores (PT), sendo o Mensalão o grande destaque no primeiro governo Lula (2003-06), sucedido pelos casos de corrupção na Petrobras (Petrolão). Tudo isso aprofundou o sentimento da população na impunidade de políticos brasileiros, o descrédito com o setor político (à esquerda, ao centro e à direita) a ponto de despertar o desejo por alternativas fora do sistema político, ou seja: um antissistema.

Durante sua trajetória de oposicionista, construída ao longo dos governos Fernando Henrique Cardoso (FHC), Lula e Dilma, Jair Bolsonaro atuou como político antissistema, ou seja, sendo visto como um político fora dos acordos políticos tradicionais, apesar de possuir décadas de mandatos pessoais e familiares (Vargas et al., 2018). Nesse sentido, Mouffe (2005) já alertava para um aumento crescente de pessoas desiludidas com os partidos tradicionais, e consequentemente, aderindo a partidos de extrema-direita por atenderem seus interesses.

Em 2018, Bolsonaro se candidatou a presidente do Brasil, político de extrema-direita que possui uma retórica agressiva e autoritária em seus discursos, utilizou-se de pautas dos costumes, discurso contra a corrupção, utilização de símbolos nacionais como a bandeira e referências religiosas como a Bíblia e o cristianismo para conquistar seus eleitores. Para Iraheta (2018) destacam-se as suas principais bandeiras políticas: 1 - ser o anti-PT, 2 - ser anti-establishment (anti-sistema) da política tradicional, 3 -vontade de mudança dos eleitores, 4 - resolver a crise econômica e 5 - resolver o problema da violência urbana.

Diante disso, é possível afirmar que Jair Bolsonaro possui o estilo político de líder populista, homem-forte carismático, que mobiliza as massas e conduz o seu partido o Partido Social Liberal (PSL) a implementar reformas radicais na política brasileira (Mudde \& Kaltwasser, 2017).

Corrobora neste perfil populista a afirmação Lincolins et al. (2018) que dizem:

populismo também exige um populista: o grande líder que encarna a vontade do povo. Quase inevitavelmente um homem, com a capacidade de denunciar em palavras suficientemente agressivas os inimigos do povo. Com ou sem a ajuda do Estado, um culto à personalidade existe em torno do líder. Os ataques à oposição podem ficar só no verbal ou passar a diversos abusos ilegais, [...]. As eleições continuam, mas a distinção entre uma democracia dominada por populismo e um regime autoritário pode se tornar nebulosa (Lincolins et al., 2018).

De modo a caracterizar o discurso da candidatura de Jair Bolsonaro recorremos ao estudo do Programa de Pós-Graduação de Ciências Sociais em Desenvolvimento de Agricultura e Sociedade da Universidade Federal do Rio de Janeiro (CPDA/UFRRJ) 
liderados por Vargas et al. (2018). Neste estudo foram encontradas, reconhecidas, selecionadas e analisadas um conjunto importante de falas, textos e/ou retóricas expressas em eventos públicos (palanques de comícios, anúncios televisivos e entrevistas), declarações à imprensa, mensagens e postagens nas redes sociais, que foram feitas ou expressas desde o segundo semestre de 2017 até agosto de 2018. Por um lado, o "Nós", Cidadãos de bem e o "Eles", Esquerdistas conforme Tabela 4 (grifo nosso):

Tabela 4. Características do Discurso de Jair Bolsonaro

\begin{tabular}{|c|c|}
\hline Nós & Eles \\
\hline Cidadãos de bem: segurança e moral & $\begin{array}{l}\text { Esquerdismo: bandidagem, imoralidade e } \\
\text { corrupção }\end{array}$ \\
\hline Família & Gays e homossexuais \\
\hline $\begin{array}{l}\text { Defensores do controle da natalidade e da redução } \\
\text { da maioridade penal }\end{array}$ & Ativistas de direitos humanos \\
\hline Defensores dos valores cristãos conservadores & Socialistas e sociais-democratas \\
\hline Homens & Mulheres \\
\hline Defensores da Escola sem Partido & Doutrinadores de Paulo Freire e Gramsci \\
\hline Armamentistas e milícias & $\begin{array}{c}\text { Desarmamentistas e defensores dos direitos } \\
\text { humanos }\end{array}$ \\
\hline Policiais e militares & $\begin{array}{l}\text { Intelectuais, jornalistas, protetores de traficantes e } \\
\text { estrupadores }\end{array}$ \\
\hline Agronegócio e segurança no campo & $\begin{array}{l}\text { Indígenas, quilombolas, sem-terra e terroristas do } \\
\text { campo }\end{array}$ \\
\hline Proprietários e livre iniciativa & $\begin{array}{l}\text { Invasores da propriedade privada, movimentos } \\
\text { sociais e comunistas }\end{array}$ \\
\hline Mérito, jovens que querem subir na vida & Cotistas, bolsistas e refugiados \\
\hline Patriotas & Políticos corruptos e Fórum de São Paulo \\
\hline
\end{tabular}

Fonte: Utilização do método de análise do discurso "Nós” e "Eles” de Vargas, et al., (2018).

Vargas et al. (2018) definem as principais características do discurso de Bolsonaro: Da mesma forma que na definição do "Nós", mas com o sentido inverso, o "Eles", esquerdistas é também um significante vazio que está associado à bandidagem, imoralidade e corrupção. Através da cadeia de equivalências, "esquerdista" enquanto o principal inimigo, se desdobra em grupos sociais específicos: os gays e homossexuais; mulheres; ativistas de direitos humanos; defensores do desarmamento; indígenas, quilombolas, sem-terra que seriam terroristas do campo; invasores da propriedade privada, movimentos sociais e comunistas; cotistas, bolsistas e refugiados; intelectuais, jornalistas, protetores de traficantes e estupradores; socialistas e social-democratas, doutrinadores de Paulo Freire e Gramsci. Em síntese, os anti-patriotas: os políticos corruptos, e sobretudo os esquerdistas do Fórum de São Paulo (Vargas, et al., 2018). 
Jair Bolsonaro utiliza-se de certo modo de uma política com viés Macartista (em inglês McCarthyism), ou seja, prática de acusar alguém de subversão, traição (ao Brasil), e constantemente acusa os adversários sobre o manto de uma ameaça comunista dos esquerdistas vermelhos do PT. O Marcatismo é também caracterizado por uma retórica política feita de ataques demagógicos ao caráter ou ao senso de patriotismo dos seus adversários políticos. Laclau (2005) corrobora este pensamento ao afirmar que nos Estados Unidos o Macartismo utilizou-se de todo arsenal ideológico populista para atacar seus adversários.

Nas eleições do ano de 2018, era corriqueiro ver nas recepções dos aeroportos seus simpatizantes chamando-o de Mito, por admirarem suas posições contra as mulheres dos movimentos feministas, homossexuais, os direitos humanos, e concordando com sua afirmação que bandido bom é bandido morto (grifo nosso). De acordo com Ianni (1968, p. 219) “o populismo sempre foi, malgrado as distorções político-ideológicas que lhe são inerentes, um mecanismo de politização das massas".

Portanto, seus discursos carregam forte apelo emocional e são particularmente agressivos. É na forma da dimensão moral que Bolsonaro persegue o objetivo político de mobilizar, e armar os Cidadãos de bem (grifo nosso) e construir pontes com seu eleitorado. Mudde \& Kaltwasser (2017) afirmam que em grande parte os populistas detestam o establishment político, como criticam a elite cultural, dos midea e a elite econômica, apesar da distinção ser meramente moral.

Deste modo, nas diversas situações os conjuntos de elementos estabelecidos no seu discurso constituem cadeias de valores, com o objetivo claro de distinguir os aliados que reúnem as características positivas e os seus adversários nesse caso, o inimigo que deve ser combatido na sociedade, que é considerado como negativo e/ou a ser ultrapassado por um novo modelo, uma nova hegemonia (Vargas et al., 2018). Huntington (2001, p. 376) afirma que "o que as pessoas têm mais em comum é mais o sentido de um inimigo [ou mal] comum do que o empenhamento numa cultura comum".

Almeida (2019) afirma que uma das principais linhas de discurso de Bolsonaro foram as pautas dos costumes, questões relativas ao corpo e ao comportamento, articulação com uma base parlamentar evangélica, combate a chamada "ideologia de gênero", tudo isso como forma de convencer os eleitores conversadores, defensores da família, cristãos conservadores, os cidadãos de bem.

O lema de campanha de Bolsonaro era: "Brasil acima de tudo, Deus acima de todos". Para os seus críticos, o destaque obtido por Bolsonaro é fruto do contexto onde medo, ressentimento e raiva são estimulados, e os preconceitos e as posturas antirrepublicanas emergem, fertilizando o terreno para a propagação de um extremismo radical.

Outra característica importante no discurso de Jair Bolsonaro é o constante apelo em dizer que será diferente dos demais políticos, e que vai expulsar os "vermelhos" do PT da pátria, bem como a afirmação de que o ex-presidente Lula irá mofar na cadeia, demonstram claramente através destas declarações uma retórica populista 
extremista. Nesse sentido, Almeida (2019) destaca que o discurso contra a corrupção da velha política, representada pelo lulopetismo, consolidou Bolsonaro como pólo de oposição e alternativa ao petismo, apresentando assim o Bolsonarismo.

\section{Considerações Finais}

No final do século 20, o populismo parecia sepultado. Após o fim da União Soviética e da queda do muro de Berlim, a democracia liberal - e o modelo neoliberal, parecia consolidado como a única opção exequível. Era "o fim da história" proclamado por Francis Fukuyama (1999), cientista político americano. Entretanto, a história continua a ser realizada, onde a esquerda na América Latina se reorganizou com o propósito de realizar uma revolução pelo voto e não pelas armas.

Deste modo surgiram diversos líderes carismáticos com viés populista de esquerda, Nestor Kirchner da Argentina, Evo Molares da Bolívia, Rafael Correa do Equador, Hugo Chávez da Venezuela e Lula da Silva do Brasil. Ocorre que hoje o populismo em ascensão está no outro campo político, da direita, ou extrema direita radical. De acordo com Mudde \& Kaltwasser (2017) os populistas com mais sucesso são de direita, especialmente na direita radical, como: Donald Trump, nos Estados Unidos, Marine Le Pen, na França, Vladimir Putin, na Rússia e Rodrigo Duterte, nas Filipinas, pois combinam nacionalismo e autoritarismo com populismo. Na atualidade, na falta de semelhantes latino-americanos, Jair Bolsonaro já foi caracterizado como "Trump Tropical”, Trump dos Trópicos e Duterte Ocidental que lhe são características alusivas por se tornar o mais recente representante populista latino-americano.

Mouffe (2016) afirma que o populismo de direita tem eco em setores sociais cada vez numerosos, e que é urgente perceber que para combater esse tipo de populismo, a condenação moral e a demonização de seus apoiadores não funcionam. A única maneira de impedir o surgimento de tais partidos e de se opor aos já existentes é a construção de outro povo, promovendo um movimento populista progressista e receptivo a essas aspirações democráticas, orientando-as para a defesa da igualdade e da justiça social.

O fenômeno do populismo não é privilégio de direita ou esquerda. Por mais que sejam distintos os populistas nesses dois campos e propostas eles seguem os mesmos termos básicos. Quando Donald Trump, presidente dos Estados Unidos, e Nicolás Maduro, presidente da Venezuela falam em "povo", estão se referindo a maioria. O populismo é uma forma de profundo majoritarismo, que rejeita enfaticamente os direitos das minorias (Lincolins et al., 2018).

O contributo presente centrou-se na análise das características do discurso populista de Jair Bolsonaro. O material recolhido tem por base o levantamento bibliográfico. O estudo efetuado leva-nos a concluir que o que é peculiar no populismo de Jair Messias Bolsonaro é a combinação de um discurso extremista a uma atitude política populista de direita radical. 
O discurso populista de Bolsonaro dialoga claramente com o senso comum das pessoas, flertando, porém, com a pregação do ódio e do medo como bandeiras de campanhas. No senso comum, seu discurso encontra ampla ressonância nas pessoas, por ter sido oposicionista há muitos anos foi caracterizado como um político "antissistema" e nos jovens através das redes sociais o seu discurso encontra sentido e coesão para este segmento.

Jair Bolsonaro faz ainda o jogo político, típico de populista, no qual reclama para si a representação de um "povo" formado especificamente por seus correligionários, ao passo em que afirma que a oposição não tem legitimidade alguma, sendo equiparados a antipátria. Sendo um líder carismático nato, seus discursos apelam para o autoritarismo e apresenta grandes desprezo as instituições democráticas e a institucionalidade da regra do jogo.

A retórica eleitoral de Bolsonaro caracterizou-se principalmente por enfatizar o "povo" contra a "elite", o "Nós", Cidadãos de bem contra "Eles", os Esquerdistas, características empíricas de um populismo de baixa intensidade evidente como o idealizado de acordo com os autores Mudde \& Kaltwasser (2017) que dividia a sociedade em dois grupos antagônicos o "povo puro" versus a "elite corrupta".

Data de receção: 31/01/2019

Data de aprovação: 22/11/2019

\section{Referências}

Almeida, R. (2019). Bolsonaro Presidente: Conservadorismo, Evangelismo e a crise brasileira. Novos Estudos Cebrap, v. 38 no.1, 185-213.

Amado, G. (2017). Bolsonaro é um 'populista perigoso', diz professor de Stanford - Jornal O Globo. Acesso em 26 de Dezembro de 2018, disponível em: <https://oglobo.globo.com/ brasil/bolsonaro-um-populista-perigoso-diz-professor-de-stanford-22029047>.

Baquero, M. (2010). Populismo e neopopulismo na América Latina: o seu legado nos partidos e na cultura política. Sociedade e Cultura, 13 (2), 181-192.

Carneiro, G. O. P. (2009). A Nova Maioria: Determinantes do Apoio Político ao Neopopulismo na América Latina (Tese de Doutorado). Faculdade de Filosofia, Letras e Ciências Humanas, Universidade de São Paulo, São Paulo, SP, Brasil.

Fukuyama, F. (1999). O Fim da História e o Último Homem (2a ed.). (M. Goes, Trad.) Lisboa: Gradiva.

Galito, M. S. (2017). Populismo - conceptualização do fenômeno. Instituto Superior de Economia e Gestão - CEsA/CSG. Acesso em 03 de Janeiro de 2018, disponível em Instituto Superior de Economia e Gestão - CEsA/CSG Documentos de Trabalho n 158-2017: http://hdl.handle.net/10400.5/14156

Gidron, N., e Bonikowski, B. (2013). Varieties of Populism: Literature Review and Research Agenda. Weatherhead Center for International Affairs, Harvard University, Working Paper Series, N. 13-0004, pp. 1-38. 
Huntington, S. P. (2001). O Choque das Civilizações (2a ed.). (H. M. Ribeiro, Trad.) Lisboa: Gradiva.

Ianni, O. (1968). O colapso do Populismo no Brasil. Rio de Janeiro: Civilização Brasileira.

Iraheta, D. (2018). 6 motivos porque Jair Bolsonaro foi eleito presidente do Brasil. Huffpost. Acesso em 20 de Janeiro de 2018. Disponível em: <https://www.huffpostbrasil. com/2018/10/29/6-motivos-por-que-jair-bolsonaro-foi-eleito-presidente-do-brasil_a_23574470/>.

Lincolins, T., Yazbek, L., \& Vasconcellos, L. (25 de Outubro de 2018). AH - Aventuras na História. Acesso em 15 de Janeiro de 2018, disponível em Aventuras na História: <https:// aventurasnahistoria.uol.com.br/noticias/reportagem/historia-populismo.phtml>.

Laclau, E. (2005). On Populist Reason. London: Verso.

Mendonça, D. d. (2014). Populismo como vontade de democracia. Colombia Internacional 82, pp. 51-70.

Mouffe, C. (1996). O Regresso do Político (1 $1^{\text {a }}$ ed.). (A. S. Simões, Trad.) Lisboa: Gradiva.

Mouffe, C. (2000). The Democratic Paradox. London: Verso.

Mouffe, C. (2005). Por um Modelo Agonístico da Democracia. Revista de Sociologia e Política 25, 11-23, pp. 11-23.

Mouffe, C. (2016). The populist moment - Open Democracy. Acesso em 20 de Maio de 2019, disponível em: <https:/www.opendemocracy.net/en/democraciaabierta/populist-moment/>.

Mudde, C., \& Kaltwasser, C. R. (2017). Populismo uma brevíssima introdução (1 $1^{\text {a }}$ ed.). (M. d. Carmo, Trad.) Lisboa: Gradiva.

Pasquino, G. (2010). Curso de Ciência Política (2a ed.). (A. S. Mota, Trad.) Cascais: Principia.

Vargas, A. L. B., Romano, J. O., Feitosa, A. C., Balthazar, P. A. A., Bittencourt, T. P. \& Barbosa, Y. R. S. (2018). O discurso político de Bolsonaro: Cidadãos de bem, segurança e moral Le Monde Diplomatique. Acesso em 27 de Dezembro de 2018, disponível em: <https:// diplomatique.org.br/o-discurso-politico-de-bolsonaro-cidadaos-de-bem-seguranca-e-moral/>. 


\section{Agradecimentos}

A minha esposa e ao meu filho, sem os quais nada faria sentido.

\section{Sobre o autor}

Vinicius Albernaz bacharel em Administração pela Universidade Federal do Tocantins UFT (Brasil), especialista em Ciências Políticas e atualmente Mestrando em Ciência Política pela Universidade da Beira Interior - UBI (Portugal). É servidor público no Brasil, atuando na área de Saúde no Estado do Tocantins. Possui interesse em temáticas relacionadas como: ciência política, juventude e gestão de pessoas. Foi premiado no Brasil com menção honrosa pela realização do Projeto Parlamento Jovem - gerando artigos científicos para Revistas Científicas, sendo apresentado no Encontro de Pesquisadores de Políticas de Juventude em Brasília-DF, na Conferência Nacional de Juventude e no Congresso Brasileiro de Extensão Universitária, disponíveis no Curriculum Lattes.

\section{About the author}

VINICIUS ALBERnaz bachelor of Business Administration from the Federal University of Tocantins - UFT (Brazil), Specialist in Political Science and Master's Student in Political Science at the University of Beira Interior - UBI (Portugal). He is a public servant in Brazil, working in the health area in the state of Tocantins. Has interest in related topics such as: political science, youth and people management. He was awarded in Brazil with honorable mention for the accomplishment of the Youth Parliament Project - generating scientific articles for Scientific Journals being presented at the Meeting of Youth Policy Researchers in Brasilia-DF, the National Youth Conference and the Brazilian Congress of University Extension, available in the Curriculum Lattes. 